\title{
THE
}

\section{Dietary antioxidants and flight exercise in female birds affect allocation of nutrients to eggs: how carry-over effects work}

\author{
Megan M. Skrip \\ University of Rhode Island \\ Navindra P. Seeram \\ University of Rhode Island, nseeram@uri.edu \\ Tao Yuan \\ University of Rhode Island \\ Hang Ma \\ University of Rhode Island, hang_ma@uri.edu \\ Scott R. McWilliams \\ University of Rhode Island, srmcwilliams@uri.edu
}

Follow this and additional works at: https://digitalcommons.uri.edu/nrs_facpubs

Terms of Use

All rights reserved under copyright.

\section{Citation/Publisher Attribution}

Skrip, M. M., Seeram, N. P., Yuan, T., Ma, H., \& McWilliams, S. R. (2016). Dietary antioxidants and flight exercise in female birds affect allocation of nutrients to eggs: how carry-over effects work. Journal of Experimental Biology, 219, 2716-2725. doi: 10.1242/jeb.137802

Available at: http://dx.doi.org/10.1242/jeb.137802

This Article is brought to you for free and open access by the Natural Resources Science at DigitalCommons@URI. It has been accepted for inclusion in Natural Resources Science Faculty Publications by an authorized administrator of DigitalCommons@URI. For more information, please contact digitalcommons-group@uri.edu. 


\title{
Dietary antioxidants and flight exercise in female birds affect allocation of nutrients to eggs: how carry-over effects work
}

\author{
Megan M. Skrip ${ }^{1, *}$, Navindra P. Seeram², Tao Yuan ${ }^{2,3}$, Hang Ma² and Scott R. McWilliams ${ }^{1}$
}

\begin{abstract}
Physiological challenges during one part of the annual cycle can carry over and affect performance at a subsequent phase, and antioxidants could be one mediator of trade-offs between phases. We performed a controlled experiment with zebra finches to examine how songbirds use nutrition to manage trade-offs in antioxidant allocation between endurance flight and subsequent reproduction. Our treatment groups included (1) a non-supplemented, non-exercised group (control group) fed a standard diet with no exercise beyond that experienced during normal activity in an aviary; (2) a supplemented non-exercised group fed a water- and lipid-soluble antioxidantsupplemented diet with no exercise; (3) a non-supplemented exercised group fed a standard diet and trained to perform daily endurance flight for 6 weeks; and (4) a supplemented exercised group fed an antioxidant-supplemented diet and trained to perform daily flight for 6 weeks. After flight training, birds were paired within treatment groups for breeding. We analyzed eggs for lutein and vitamin $\mathrm{E}$ concentrations and the plasma of parents throughout the experiment for non-enzymatic antioxidant capacity and oxidative damage. Exercised birds had higher oxidative damage levels than non-exercised birds after flight training, despite supplementation with dietary antioxidants. Supplementation with water-soluble antioxidants decreased the deposition of lipid-soluble antioxidants into eggs and decreased yolk size. Flight exercise also lowered deposition of lutein, but not vitamin $\mathrm{E}$, to eggs. These findings have important implications for future studies of wild birds during migration and other oxidative challenges.
\end{abstract}

KEY WORDS: Antioxidant capacity, Lipid oxidation, Repeated measures, Reproduction, Songbirds

\section{INTRODUCTION}

Physiological challenges during part of the annual cycle (e.g. spring migration) can carry over and affect performance at subsequent phases (e.g. reproduction; Ebbinge and Spaans, 1995; Bauchinger et al., 2009; Legagneux et al., 2012), although the mechanisms that produce these carry-over effects are only rarely understood (Harrison et al., 2011). A particularly interesting but understudied potential mechanism for carry-over effects impacting reproductive

${ }^{1}$ Department of Natural Resources Science, University of Rhode Island, 105 Coastal Institute in Kingston, 1 Greenhouse Road, Kingston, RI 02881, USA. ${ }^{2}$ Bioactive Botanical Research Laboratory, Department of Biomedical and

Pharmaceutical Sciences, College of Pharmacy, 7 Greenhouse Road, University of Rhode Island, Kingston, RI 02881, USA. ${ }^{3}$ The Key Laboratory of Plant Resources and Chemistry of Arid Zone, State Key Laboratory of Xinjiang Indigenous Medicinal Plants Resource Utilization, Xinjiang Technical Institute of Physics and Chemistry, Chinese Academy of Sciences, Urumqi 830011, China.

*Author for correspondence (megan_skrip@my.uri.edu)

(D) M.M.S., 0000-0001-7972-7330

Received 22 January 2016; Accepted 23 June 2016 performance concerns the antioxidant system and its ability to quench pro-oxidants. Generally, antioxidants provided to embryos are considered beneficial (Saino et al., 2003; McGraw et al., 2005; Berthouly et al., 2007, 2008; Marri and Richner, 2014; Jacob et al., 2015); however, if antioxidant supply is limited and requirements prior to reproduction are relatively high, then a female's allocation of antioxidants to reproduction could be restricted and thus produce an important carry-over effect.

Birds rely on suites of antioxidant compounds, both ingested and internal, to intercept and neutralize pro-oxidants before they cause oxidative damage. Evidence suggests that wild birds seek out and acquire dietary antioxidants while migrating (Alan et al., 2013; Bolser et al., 2013), using resources on stopover sites to increase antioxidant capacity in preparation for their flights (Skrip et al., 2015). Any surplus antioxidants remaining after migration might be deposited into eggs on breeding grounds, but no research has investigated this carry-over phenomenon. Migratory birds typically begin breeding shortly after spring migration, and the endurance flights they recently performed might impact their oxidative state (e.g. Skrip et al., 2015) and ability to allocate antioxidants. Although many studies have examined how maternal diet affects the deposition of antioxidants into eggs (e.g. Royle et al., 2003; McGraw et al., 2005; Blount et al., 2006), none have considered how using antioxidants during flight could affect subsequent investment of antioxidants during reproduction. Previous studies of egg composition and flight performance have focused on lipidsoluble carotenoids and vitamin E. Plasma levels of carotenoids can relate to dietary intake (Koutsos et al., 2003), and vitamin E is considered especially important to embryos (Surai, 2002). Watersoluble polyphenolic compounds such as anthocyanins, however, are powerful antioxidants with high concentrations in fruits consumed by wild birds (Alan et al., 2013; Bolser et al., 2013), and their contribution to avian antioxidant capacity is emerging as an important area of research (Catoni et al., 2008; Schaefer et al., 2008; Beaulieu and Schaefer, 2013, 2014). Dietary anthocyanins circulate in avian plasma and can help songbirds mount an immune response (Catoni et al., 2008); birds may even select fruits based on their anthocyanin content (Schaefer et al., 2008; Bolser et al., 2013).

We performed a controlled experiment with zebra finches (Taeniopygia guttata Vieillot) to determine the combined effects of food chemistry - specifically, a blend of lipid- and water-soluble dietary antioxidants - and the demands of flight on the allocation of nutrients to eggs in songbirds. This is the first experiment to combine fat- and water-soluble antioxidants in a supplement for songbirds and to test for effects of dietary antioxidants and longduration flight exercise on egg composition. Although not migratory, zebra finches offer many opportunities for mechanistic studies and are used often as model organisms, given that they breed readily in the laboratory and lend themselves to experimental treatments that cannot be accomplished with wild birds (Griffith and Buchanan, 2010). Studies using zebra finches have shown that diet, 
body condition and mate attractiveness affect antioxidant deposition into eggs (Royle et al., 2003; McGraw et al., 2005; Williamson et al., 2006); that egg composition and the diet of young birds affect their antioxidant capacity later in life (Blount et al., 2003; McGraw et al., 2005); and that dietary antioxidant supplementation improves exercise performance in adult birds (Blount and Matheson, 2006). Zebra finch eggs containing high antioxidant levels also have low concentrations of pro-oxidants, are more likely to hatch, and produce young more likely to survive the nestling stage (McGraw et al., 2005).

In this experiment, we tested the following hypotheses regarding the impact of dietary antioxidants and exercise on the oxidative status of adult songbirds and allocation of antioxidants to eggs. Hypothesis 1: endurance flight poses an oxidative challenge. We expected exercised birds to have higher levels of oxidative damage (measured by the presence of circulating hydroperoxides) after flight training than non-exercised birds. Several studies have associated long-distance flight with oxidative damage in freeflying birds (trained pigeons, Columba livia: Costantini et al., 2008; migrating European robins, Erithacus rubecula: JenniEiermann et al., 2014) and acute flight bouts with oxidative damage in captive birds (zebra finches: Costantini et al., 2013); our results, in a controlled setting, would support that endurance flight poses an oxidative challenge to songbirds. Hypothesis 2: dietary antioxidants contribute to antioxidant protection in birds. We expected supplemented birds to display higher antioxidant capacity and lower oxidative damage than non-supplemented birds. If birds build antioxidant capacity by acquiring dietary antioxidants (as suggested by Beaulieu and Schaefer, 2014, and Skrip et al., 2015), our results would support a mechanism for antioxidant protection. Hypothesis 3: flight and diet exert effects on subsequent breeding. Based on feeding studies by other researchers who used solely lipid-soluble dietary antioxidants (e.g. McGraw et al., 2005), we expected that supplemented birds would lay eggs with higher lipid-soluble antioxidant concentrations than non-supplemented birds. We also expected that exercised birds would lay eggs with lower antioxidant concentrations than nonexercised birds, given that available antioxidants should be used during flight.

\section{MATERIALS AND METHODS}

All captive work was approved by the University of Rhode Island's Institutional Animal Care and Use Committee (IACUC no. AN1112-009). Our experimental design was $2 \times 2$ factorial, with two diet treatments and two exercise treatments among four groups of adult zebra finches: (1) a non-supplemented, non-exercised group (control group) fed a standard diet with no exercise beyond that experienced during normal activity in an aviary; (2) a supplemented non-exercised group fed an antioxidant-supplemented diet with no exercise; (3) a non-supplemented exercised group fed a standard diet and trained to perform daily endurance flight; (4) a supplemented exercised group fed an antioxidant-supplemented diet and trained to perform daily flight. The timeline of the experiment involved a 4 month diet acclimation period followed by three sequential phases: a 4 week diet supplementation phase, a 6 week exercise phase and a breeding phase (Fig. 1). During the diet supplementation phase and exercise phase, we housed zebra finches in four same-sex indoor aviaries $(2.1 \times 0.9 \times 1.8 \mathrm{~m}, \mathrm{~L} \times \mathrm{W} \times \mathrm{H}$; initial stocking=19-21 birds per aviary) on a $14 \mathrm{~h}: 10 \mathrm{~h}$ light:dark cycle under full-spectrum light, with lights on at 06:00 h. During the breeding phase, we housed mating pairs in individual cages $(0.6 \times 0.4 \times 0.35 \mathrm{~m}, \mathrm{~L} \times \mathrm{W} \times \mathrm{H})$ with nesting material.

\section{Phase I: diet treatment}

For 4 months before the diet phase, all birds were provided daily ad libitum water, cuttlebone, grit and standard seed mixture (Kaytee ${ }^{\circledR}$ Supreme ${ }^{\mathrm{TM}}$ Finch mix), plus kale twice weekly, to acclimate them to the lab environment. Half of the birds (two of the same-sex aviaries; $N=17$ females, $N=19$ males) remained on this non-supplemented diet while the other birds were assigned to a supplemented (highantioxidant) diet ( $N=15$ females, $N=17$ males) on which they remained for the subsequent 4 week diet supplementation phase and exercise and breeding phases.

The supplemented group received cuttlebone, grit, standard seed mixture and kale twice weekly, plus ad libitum water supplemented with lipid-soluble antioxidants $(4.0 \mu \mathrm{g}$ FloraGLO 10\% lutein beadlets per ml; DSM Nutritional Products Ltd, Parsippany, NJ, USA) and water-soluble antioxidants (3.2 mg Standard Elderberry Powder 25\% per $\mathrm{ml}$; Artemis International, Inc., Fort Wayne, IN, USA). The elderberry powder was produced by spray-drying elderberry extract and standardized to $\geq 25 \mathrm{~g} / 100 \mathrm{~g}$ anthocyanin, expressed as cyanidin3 -glucoside on a maltodextrin excipient; the powder also contained $>40 \mathrm{~g} / 100 \mathrm{~g}$ polyphenols, expressed as catechin (Artemis International, Inc.). Thus, water-soluble supplementation contained two types of flavonoids: catechins and anthocyanins.

The concentration of lutein was based on average seed and water consumption of the study animals, to attain dosages used by other researchers for zebra finches (McGraw et al., 2004, 2005). These authors evaluated the lutein content of seed and raised the dosage to presumably the upper limit of what birds might naturally encounter (McGraw et al., 2001, 2004). Lutein is a lipid-soluble antioxidant found in seed and a pigment in both beaks and feathers (McGraw et al., 2004). It is one of the main carotenoids in the finches' seed diet (McGraw et al., 2001). McGraw et al. (2005) used daily consumption rates of seed and water to estimate that birds derived ca. $15 \mu \mathrm{g}$ lutein day $^{-1}$ from seed (Kaytee ${ }^{\circledR}$ Forti-Finch ${ }^{\mathrm{TM}}$ mix) and ca. $18 \mu \mathrm{g}$ lutein day ${ }^{-1}$ from supplementation to the drinking water, totaling ca. $33 \mu \mathrm{g}$ lutein day ${ }^{-1}$ bird $^{-1}$. Based on measurement of seed $\left(3.5 \mathrm{~g} \mathrm{day}^{-1}\right)$ and water $\left(3.5 \mathrm{ml} \mathrm{day}{ }^{-1}\right)$ consumption of finches in our study, we estimated that the birds derived ca. $18 \mu \mathrm{g}$ lutein day $^{-1}$ from seed (Kaytee ${ }^{\circledR}$ Supreme ${ }^{\mathrm{TM}}$ Finch mix) and ca. $14 \mu \mathrm{g}$ lutein day $^{-1}$ from supplementation to the drinking water, totaling ca. $32 \mu \mathrm{g}$ lutein day ${ }^{-1}$ bird $^{-1}$.

We chose the anthocyanin concentration to approximate that used by researchers studying the effects of anthocyanin supplementation on food choice and immunocompetence in European blackcaps (Sylvia atricapilla; Catoni et al., 2008; Schaefer et al., 2008). These blackcaps consumed $2.8 \mathrm{mg}$ anthocyanin $\mathrm{day}^{-1}$, in the form of a standardized 50\% anthocyanin extract; the researchers based their dose on 'estimates of flavonoid ingestion by blackcaps during periods of relatively low frugivory $\left(<10\right.$ berries day $^{-1}$ )' (Catoni et al., 2008, p. 651). We calculated a similar dosage with a standardized $25 \%$ extract and based the delivered concentration on an average daily water consumption of $3.5 \mathrm{ml} \mathrm{day}^{-1}$.

We chose a 4 week diet supplementation period before beginning flight training, assuming this interval was long enough to affect the antioxidant capacity of zebra finches. McGraw et al. (2004) demonstrated changes in zebra finch beak color (indicating carotenoids were assimilated in tissue) using 4 weeks of carotenoid supplementation. McGraw et al. (2005) used a 3 week diet treatment to find that zebra finches fed a carotenoidsupplemented diet produced eggs with higher carotenoid content and better resistance to pro-oxidants; supplemented females also produced more sons with deeply pigmented beaks (indicative of high carotenoid content) than those on a non-supplemented diet. 


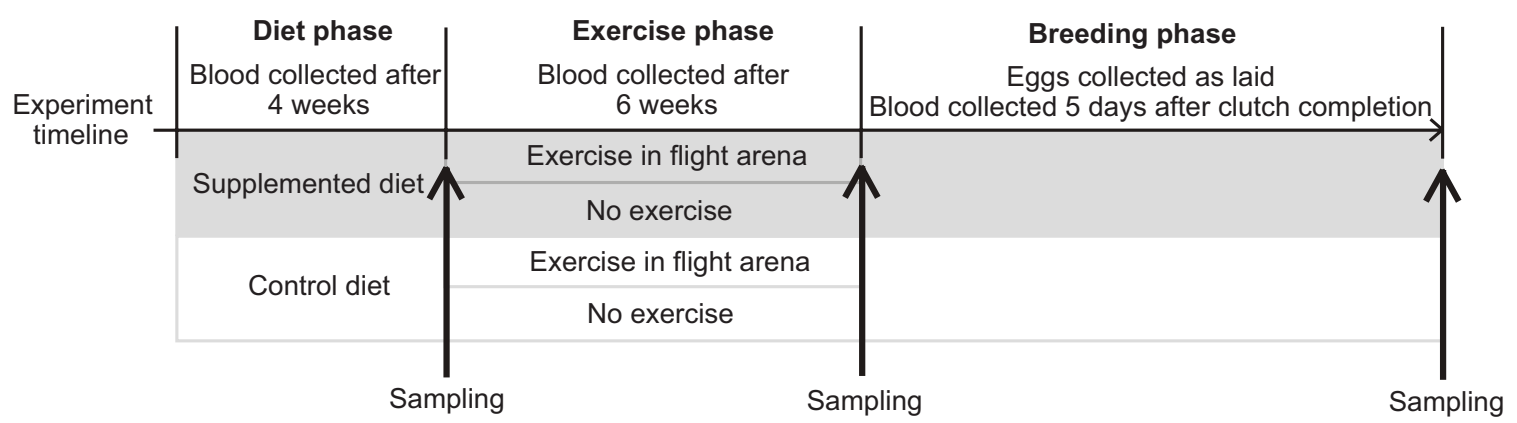

Fig. 1. Experimental timeline. The experiment consisted of three phases: a diet phase, an exercise phase and a breeding phase. We collected blood from the same individuals three times during the experiment and collected eggs as they were laid; liver tissue was collected from additional individuals after the exercise phase.

Blount and Matheson (2006) kept zebra finches on a carotenoidsupplemented diet for 8 weeks before measuring flight performance and found that supplementation improved flight times from an escape chamber; the duration of the diet treatment was not justified in their paper, and no studies have quantified the length of time necessary for an antioxidant-rich diet to impact bird flight performance. Larcombe et al. (2010) kept budgerigar parrots (Melopsittacus undulates) on a high- or low-antioxidant diet for 12 months before their flight training experiments. Given that migratory birds consume dietary antioxidants at stopover sites (Bolser et al., 2013) where they usually reside for days to at most weeks, the benefits of antioxidant consumption would have to be relatively immediate to be useful during migration.

\section{Phase Il: exercise treatment}

The exercise phase consisted of daily flight in an arena modeled on Bauchinger et al. (2010), with horizontal perch-to-perch flight totaling $6.4 \mathrm{~km} \mathrm{day}^{-1}$. Briefly, we constructed a soft-sided enclosure $(5.48 \times 1.83 \times 2.13 \mathrm{~m}, \mathrm{~L} \times \mathrm{W} \times \mathrm{H})$, with a soft partition lengthwise down the center. A human observer continuously walked around the partition for $1 \mathrm{~h}$, herding the flock of 32 birds between perches and tracking the number of circuits $(N=300$ circuits $\mathrm{h}^{-1}$ ) with a hand counter. Perch-to-perch flight is an accepted method of exercise for captive zebra finches (e.g. Bauchinger et al., 2010; Costantini et al., 2013), with repeated takeoffs and short flights requiring three times the energy of sustained flapping flight (Nudds and Bryant, 2000).

Half of the birds in each diet group (half of each same-sex aviary) were randomly assigned to exercise training. Each morning, we used custom-designed capture boxes in aviaries to retrieve birds in the exercised group for training. Birds voluntarily flew into the boxes and were captured or released through a small door; therefore, exercised and non-exercised birds experienced similar handling. Exercised birds were flown every day in two $1 \mathrm{~h}$ sessions (starting at 11:00 h and 13:30 h), 7 days per week for 6 weeks, totaling $270 \mathrm{~km}$ of flight for each exercised bird. Non-exercised birds remained in aviaries while conspecifics exercised, although food and water were removed so that temporal access to food, water and dietary antioxidants was the same for exercised and nonexercised birds. After the last circuit of a flight session, a blind was lowered to block off one side of the arena, a small trapdoor was opened at one end, and the birds flew into a small cage on the other side of the trapdoor; here, they were sorted back into their same-sex diet groups. During the $1 \mathrm{~h}$ break between the two $1 \mathrm{~h}$-long daily flight sessions, all birds were provided with seed and water. Exercised birds were returned to aviaries after their second daily flight.

\section{Phase III: breeding}

After the flight phase ended on 24 August 2012, we randomly assigned birds within the four treatment groups into mating pairs and housed them individually for breeding. We checked nests daily, and eggs were collected as they were laid and replaced with plastic eggs. Each egg was weighed, then stored at $-20^{\circ} \mathrm{C}$ until analyzed for antioxidant content (Royle et al., 2003; Gil et al., 2004; Rutstein et al., 2004; Blount et al., 2006; Sandell et al., 2007). Most clutches were laid between 31 August and 11 October 2012, with one clutch completed on 3 November; there was no pattern in the timing of clutch completion by treatment.

\section{Blood sampling and analysis}

We drew blood samples thrice from the same individuals to track plasma oxidative measures in response to treatments: once after the 4 week diet supplementation phase and before the exercise phase, once after the 6 week exercise phase and before breeding, and once after completion of a clutch (Fig. 1); we considered a clutch complete if the female produced no more eggs for 5 days after collection of the final egg (Sandell et al., 2007). All blood samples (150 $\mu \mathrm{l})$ were collected within $12 \mathrm{~min}$ of entering the room at 08:00 $\mathrm{h}$ (or between chiefly $08: 00 \mathrm{~h}$ and 10:00 $\mathrm{h}$ during the breeding phase) to control for any acute changes in plasma oxidative measures associated with disturbance and handling. Blood from the brachial vein was collected into heparinized capillary tubes and centrifuged for 6 min at $10,000 \mathrm{rpm}$, and plasma was stored at $-80^{\circ} \mathrm{C}$ until analysis.

We determined circulating antioxidant capacity as the ability of a plasma sample to neutralize an oxidizing assault of hypochlorous acid, using the OXY-Adsorbent test (concentration unit $=\mathrm{mmol}^{-1}$ of $\mathrm{HClO}$ neutralized; Diacron International, Grosseto, Italy); and measured oxidative damage as the presence of circulating hydroperoxides, which include products of lipid oxidation, using the d-ROMs test (concentration unit $=\mathrm{mmol} \mathrm{l}^{-1} \mathrm{H}_{2} \mathrm{O}_{2}$ equivalents; Diacron International; see Costantini et al., 2007, for details). We chose OXY and d-ROMs as general whole-animal markers of circulating oxidative status, and to facilitate comparison of results with previous studies. We anticipated that OXY, as a measure of plasma non-enzymatic antioxidant capacity, would be particularly relevant in birds acquiring dietary antioxidants (Beaulieu and Schaefer, 2014); the d-ROMs test provides an index of damage to fats and has been shown to increase in exercised pigeons after flights (Costantini et al., 2008) and to decrease with time on stopover after flights (Skrip et al., 2015). We performed all metabolite assays using a microplate spectrophotometer (Biotek Powerwave 340, Winooski, VT, USA). We ran samples in duplicate unless a coefficient of variation $>15 \%$ was observed, in which case we ran a third replicate if sufficient plasma was available. 
We present results from parents that produced complete clutches and for which plasma was available for all three sampling periods. One male and two females were not sampled in the before-training phase and were therefore excluded from blood analysis; plasma volumes for some individuals were inadequate for performing both assays for one time period, in which case OXY was prioritized. Data from 37 individuals were therefore available for analysis of OXY results $[N=10$ ( 5 male, 5 female) for non-supplemented nonexercised, $N=9$ ( 5 male, 4 female) for supplemented non-exercised, $N=10$ ( 5 male, 5 female) for non-supplemented exercised, $N=8$ (4 male, 4 female) for supplemented exercised]. Data from 30 individuals were available for analysis of d-ROMs results $[N=7$ (5 male, 2 female) for non-supplemented non-exercised, $N=7$ (4 male, 3 female) for supplemented non-exercised, $N=9$ ( 5 male, 4 female) for non-supplemented exercised, $N=7$ ( 2 male, 5 female) for supplemented exercised].

\section{Liver sampling and analysis}

After the exercise phase, we euthanized by cervical dislocation 28 birds randomly assigned to not be part of the breeding phase, to determine the activities of three antioxidant enzymes in liver tissue (nmol enzyme $\min ^{-1} \mathrm{mg}^{-1}$ of protein). We determined total protein in liver samples using the Bio-Rad Bradford Protein Assay (Bio-Rad Laboratories, Inc., Hercules, CA, USA) and used commercial kits (Cayman Chemical Company, Ann Arbor, MI, USA) to measure the activity of glutathione peroxidase, catalase and superoxide dismutase $[N=6$ ( 3 male, 3 female) for non-supplemented non-exercised, $N=8$ (5 male, 3 female) for supplemented non-exercised, $N=8$ (5 male, 3 female) for nonsupplemented exercised, $N=6$ ( 3 male, 3 female) for supplemented exercised].

\section{Egg sampling and analysis}

We determined concentrations of lutein and vitamin $\mathrm{E}(\alpha-$ tocopherol) in yolk using reversed phase high performance liquid chromatography (RP-HPLC), generally following the methods of Williamson et al. (2006). We dissected eggs from frozen and weighed yolks and albumen on a digital balance to the nearest $0.0001 \mathrm{~g}$. For each egg, we combined $100 \mathrm{mg}$ of yolk with $0.7 \mathrm{ml} 5 \% \mathrm{NaCl}$ solution, $1 \mathrm{ml}$ ethanol and $2 \mathrm{ml}$ hexane, homogenized the mixture for $30 \mathrm{~s}$, and centrifuged it for $5 \mathrm{~min}$ at $720 \mathrm{~g}$. We then collected the hexane phase containing vitamin $\mathrm{E}$ and carotenoids, and extracted with hexane again before drying the combined collection under vacuum in a SPD1010 SpeedVac $^{\mathbb{C}}$ System. We dissolved the remaining residue in $500 \mu \mathrm{l}$ of methanol/dichloromethane $(1: 1 \mathrm{v} / \mathrm{v})$, ready for RP-HPLC analyses, which were performed on a Hitachi Elite LaChrom system consisting of an L-2130 pump, an L-2200 autosampler and an L-2455 Diode Array Detector all operated by EZChrom Elite software (Agilent Technologies, Inc., Pleasanton, CA, USA). We determined lutein and vitamin $\mathrm{E}$ concentrations (in $\mu \mathrm{g} \mathrm{g}^{-1}$ ) using a Waters Spherisorb S5ODS2, $5 \mu \mathrm{m}$ reverse-phase column, $25 \mathrm{~cm} \times 4.6 \mathrm{~mm}$ (Sigma Aldrich, St Louis, MO, USA) with a mobile phase of methanol/water $(9: 1 \mathrm{v} / \mathrm{v})$ at a flow rate of $1 \mathrm{ml} \mathrm{min}-1$. Lutein was detected as single peak at $445 \mathrm{~nm}$ and vitamin $\mathrm{E}$ at $290 \mathrm{~nm}$; peaks were identified by comparison with standards.

We collected complete clutches from 20 pairs of birds, although three of those birds (see above) were not blood sampled in the before-training period ( $N=6$ clutches for non-supplemented nonexercised, $N=5$ for supplemented non-exercised, $N=5$ for nonsupplemented exercised, $N=4$ for supplemented exercised).

\section{Statistical analysis}

All analyses were performed using SAS 9.4 software (SAS for Windows, SAS Institute, Cary NC, USA).

\section{Blood oxidative status}

We performed repeated measures analysis of variance (RM ANOVA) to determine the effects of diet and exercise treatments, and their interaction, on plasma measures of oxidative status over the course of the experiment. We also performed tests of effect slices to detect treatment group differences in antioxidant capacity and oxidative damage within or between three time periods: before flight training, after flight training (and before breeding) and after breeding. The compound symmetry (CS) covariance structure produced the best model fit for antioxidant capacity, as determined by AIC, and the heterogeneous autoregressive $[\operatorname{arh}(1)]$ covariance structure provided the best model fit for oxidative damage. We checked model residuals for homogeneity of variance and normality to verify satisfaction of model assumptions.

\section{Liver antioxidant enzymes}

We performed two-way ANOVA with an interaction term to determine the effects of diet and exercise treatments on liver enzyme activities. We checked model residuals for homogeneity of variance and normality to verify satisfaction of model assumptions.

\section{Egg composition}

In the wild, a typical clutch size for zebra finches is 5 eggs (Zann, 1996); most pairs in our study $(N=14)$ laid $<5$ eggs, but 2 pairs laid 8 eggs, 1 pair laid 9 and 3 pairs laid 6; given that there were too few pairs that laid $>5$ eggs, we truncated our analysis dataset to exclude these later-laid eggs (13 eggs from 6 pairs).

We used mixed general linear models to assess differences between treatment groups and across laying order for the following response variables: egg mass, proportion of yolk and concentration of yolk antioxidants. Mixed linear models allow the inclusion of random factors; here, we modeled random slopes and intercepts for each pair of birds, and nested eggs within pairs, thereby accounting for the uniqueness of pairs and non-independence of eggs within clutches. We further used the Kenward-Roger method to adjust denominator degrees of freedom (SAS v9.4; SAS Institute) to avoid pseudoreplication of eggs within clutches. Laying order, diet treatment and exercise treatment were included as main effects, as well as in two-way interactions and a three-way interaction. We checked model residuals for homogeneity of variance and normality to verify satisfaction of model assumptions.

\section{RESULTS}

\section{Effect of diet and exercise on circulating oxidative status} Oxidative damage

Oxidative damage did not vary with experiment phase (time, $F_{2,50}=0.06, P=0.9457$; Table 1), but was higher in males (least squares mean \pm s.e.m., $40.53 \pm 1.47 \mathrm{mmol}^{-1} \mathrm{H}_{2} \mathrm{O}_{2}$ equivalents) than in females $\left(35.95 \pm 1.69 \mathrm{mmol} \mathrm{l}^{-1} \mathrm{H}_{2} \mathrm{O}_{2}\right.$ equivalents; sex, $\left.F_{1,25}=4.14, P=0.0525\right)$. dROMs values for birds in the exercised group (40.25 $\pm 1.51 \mathrm{mmol} \mathrm{l}^{-1} \mathrm{H}_{2} \mathrm{O}_{2}$ equivalents) were on average slightly higher than those of unexercised birds (36.23 \pm $1.63 \mathrm{mmol} 1^{-1} \mathrm{H}_{2} \mathrm{O}_{2}$ equivalents; exercise, $F_{1,25}=3.27, P=0.0826$ ), although the only time period for which the difference between groups was statistically significant was after the flight phase (test of effect slices for exercise $\times$ time; $F_{1,50}=10.16, P=0.0025$; Fig. $2 \mathrm{~A}$ ). Exercised and non-exercised groups did not differ before training (test of effect slices for exercise $\times$ time; $F_{1,50}=0.83, P=0.3660$; 
Table 1. Type III tests of fixed effects for plasma oxidative damage

\begin{tabular}{lllll}
\hline Effect & $\begin{array}{l}\text { Numerator } \\
\text { d.f. }\end{array}$ & $\begin{array}{l}\text { Denominator } \\
\text { d.f. }\end{array}$ & F-value & $P$-value \\
\hline Diet & 1 & 25 & 0.08 & 0.7807 \\
Exercise & 1 & 25 & 3.27 & 0.0826 \\
Sex & 1 & 25 & 4.14 & 0.0525 \\
Time & 2 & 50 & 0.06 & 0.9457 \\
Diet×exercise & 1 & 25 & 1.36 & 0.2554 \\
Timexdiet & 2 & 50 & 1.40 & 0.2570 \\
Timexexercise & 2 & 50 & 0.70 & 0.5021 \\
Timexsex & 2 & 50 & 0.51 & 0.6056 \\
Timexdietxexercise & 2 & 50 & 1.11 & 0.3382
\end{tabular}

Plasma oxidative damage was measured by the d-ROMs test. $P \leq 0.05$ was considered significant.

Fig. 2A) or after breeding (test of effect slices for exercise $\times$ time; $F_{1,50}=0.30, P=0.5850$; Fig. $2 \mathrm{~A}$ ).

\section{Antioxidant capacity}

In contrast to oxidative damage, antioxidant capacity varied with phase in the experiment (time, $F_{2,64}=3.87, P=0.026$; Table 2), with OXY-Adsorbent test values dropping after the flight phase and
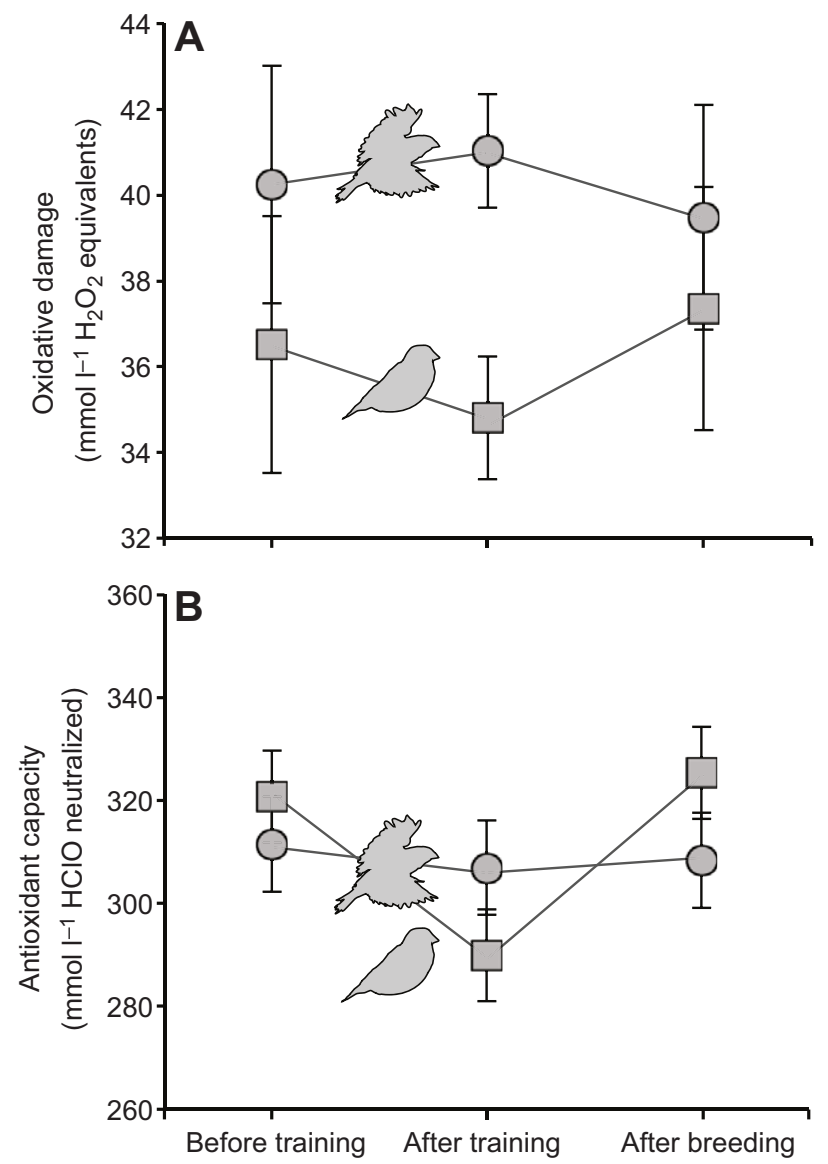

Fig. 2. Effect of diet and exercise on circulating oxidative status. (A) Plasma oxidative damage (d-ROMs test). (B) Plasma antioxidant capacity (OXY-Adsorbent test). Birds were either subjected to 6 weeks of exercise training ( $N=16$ plasma samples for damage, $N=18$ for antioxidant capacity; circles, flying bird) or were not exercise trained ( $N=14$ for damage, $N=19$ for antioxidant capacity; squares, static bird). Exercised birds displayed higher damage levels than non-exercised birds after training (repeated measures ANOVA, test of effect slices, $P=0.0025$ ). Values are shown as least square means \pm s.e.m. for the three sequential experimental phases.
Table 2. Type III tests of fixed effects for plasma antioxidant capacity

\begin{tabular}{lllll}
\hline Effect & $\begin{array}{l}\text { Numerator } \\
\text { d.f. }\end{array}$ & $\begin{array}{l}\text { Denominator } \\
\text { d.f. }\end{array}$ & F-value & $P$-value \\
\hline Diet & 1 & 32 & 1.50 & 0.2293 \\
Exercise & 1 & 32 & 0.11 & 0.7470 \\
Sex & 1 & 32 & 0.86 & 0.3600 \\
Time & 2 & 64 & 3.87 & $\mathbf{0 . 0 2 6 0}$ \\
Diet×exercise & 1 & 32 & 1.27 & 0.2680 \\
Time×diet & 2 & 64 & 1.79 & 0.1751 \\
Time×exercise & 2 & 64 & 2.84 & 0.0660 \\
Time×sex & 2 & 64 & 0.54 & 0.5857 \\
Time×diet×exercise & 2 & 64 & 2.34 & 0.1050
\end{tabular}

Plasma antioxidant capacity was measured by the OXY-Adsorbent test. Significant $P$-values $(\leq 0.05)$ are in bold.

returning to pre-flight levels after breeding. A suggested exercise $\times$ time interaction (exercise $\times$ time, $F_{2,64}=2.84, P=0.066$ ) indicates that this trend was more evident in birds that did not exercise (Fig. 2B). Furthermore, tests of effect slices show that change over time occurred only in non-exercised birds (test of effect slices for exercise $\times$ time; $F_{2,64}=6.82, P=0.0021 ;$ Fig. $2 \mathrm{~B}$ ) and not in exercised birds (test of effect slices for exercise $\times$ time; $F_{2,64}=0.09$, $P=0.9125$; Fig. 2B).

\section{Effect of diet and exercise on liver enzyme activity}

Enzyme activity varied widely within treatment groups (coefficient of variation $=15-52 \%$ ) and was not statistically different between treatments. Diet and exercise had no impact on the activity of liver glutathione peroxidase (global $F_{3,24}=1.63, P=0.2093$ ), catalase (global $F_{3,24}=0.64, P=0.5953$ ) or superoxide dismutase (global $\left.F_{3,24}=0.29, P=0.8313\right)$.

\section{Effect of diet and exercise on egg composition Lutein concentration}

Lutein concentration in egg yolk predictably decreased with laying order, but the rate of change varied by treatment group (order $\times$ diet $\times$ exercise interaction, $F_{1,61.7}=7.82, P=0.0069$; Table 3). Specifically, the non-supplemented, non-exercised group displayed a more negative slope than the other groups, which were similar to each other ( post hoc contrasts, $t>|2|, P<0.02$ ), and had a higher $y$ intercept than the other groups, which were similar to each other (post hoc contrasts, $t>|2|, P<0.02$ ). That is, pairs in the nonsupplemented, non-exercised group had initially higher concentrations of lutein in their eggs and that concentration decreased more sharply over the laying order than in the other groups (Fig. 3A).

\section{Vitamin E concentration}

Vitamin $\mathrm{E}$ concentration in egg yolk also decreased with laying order, but rate of change varied by diet group only

Table 3. Type III tests of fixed effects for a mixed GLM predicting the concentration of lutein in yolk

\begin{tabular}{|c|c|c|c|c|}
\hline Effect & $\begin{array}{l}\text { Numerator } \\
\text { d.f. }\end{array}$ & $\begin{array}{l}\text { Denominator } \\
\text { d.f. }\end{array}$ & $F$-value & $P$-value \\
\hline Order & 1 & 61.7 & 47.67 & $<0.0001$ \\
\hline Diet & 1 & 40.1 & 7.91 & 0.0076 \\
\hline Exercise & 1 & 40.1 & 1.71 & 0.1990 \\
\hline Diet×exercise & 1 & 40.1 & 11.07 & 0.0019 \\
\hline Order×diet & 1 & 61.7 & 5.27 & 0.0251 \\
\hline Order×exercise & 1 & 61.7 & 1.82 & 0.1824 \\
\hline Order $\times$ diet $\times$ exercise & 1 & 61.7 & 7.82 & 0.0069 \\
\hline
\end{tabular}

GLM, general linear model. Significant $P$-values $(\leq 0.05)$ are in bold. 

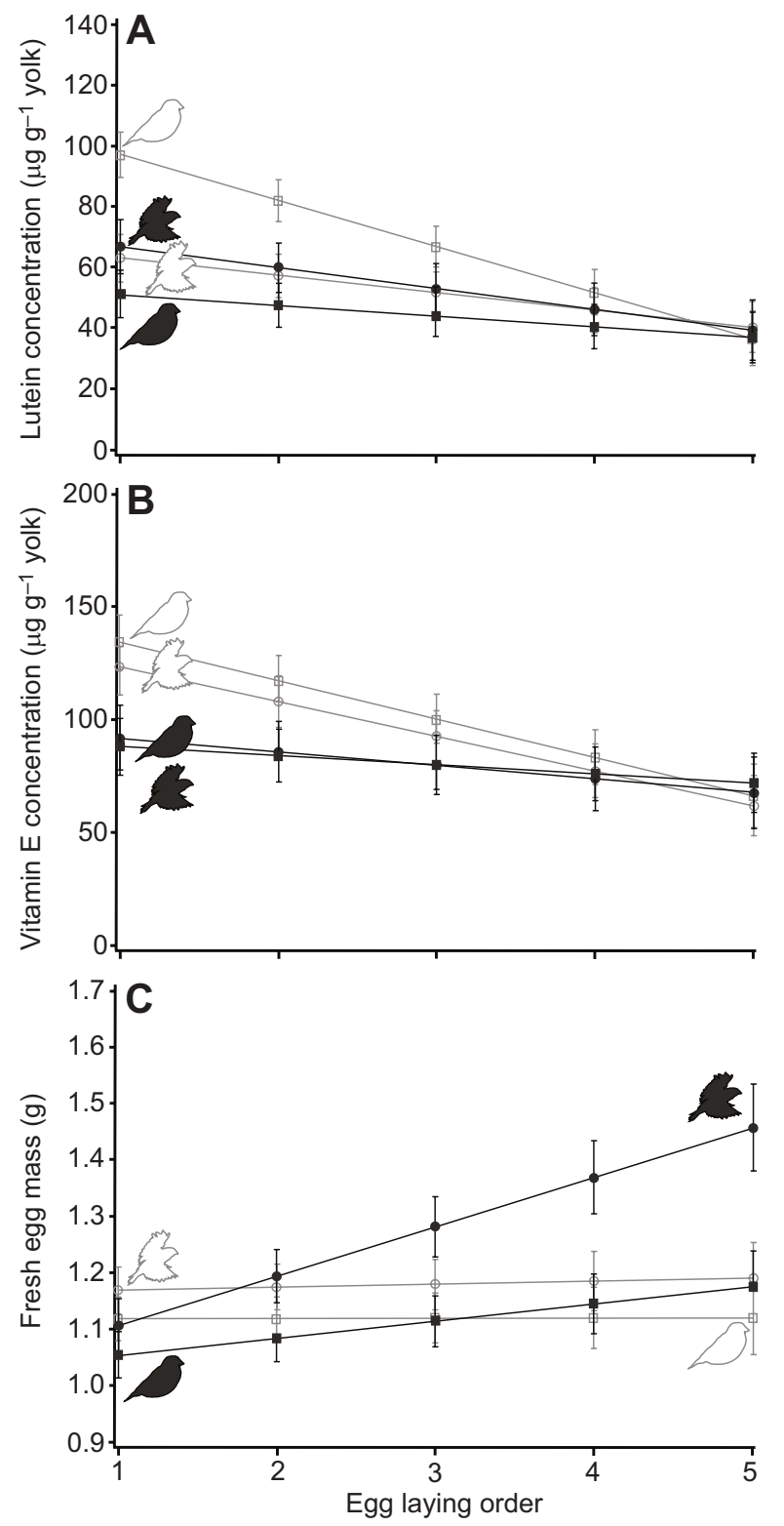

Fig. 3. Effect of diet and exercise on egg composition. Adult zebra finches were randomly paired within treatment groups, and the first 5 eggs of each pair's clutch were analyzed. (A) Yolk lutein concentration decreased with laying order, with a more negative slope in the non-supplemented, non-exercised group relative to the other groups (mixed general linear model, $P<0.05$ ). (B) Yolk vitamin $E$ concentration decreased with laying order, with a more negative slope among non-supplemented pairs relative to supplemented pairs (mixed general linear model, $P<0.05$ ). (C) Fresh egg mass increased with laying order for supplemented pairs, with a more positive slope among supplemented pairs that were also exercised (mixed general linear model, $P<0.05$ ). Open squares (open static bird): non-supplemented non-exercised, $N=6$ clutches; filled squares (filled static bird): supplemented non-exercised, $N=5$ clutches; open circles (open flying bird): non-supplemented exercised, $N=5$ clutches; filled circles (filled flying bird): supplemented exercised, $N=4$ clutches. Values are shown as least square means \pm s.e.m.

(order $\times$ diet, $\quad F_{1,61.9}=10.79, \quad P=0.0017$; Table 4, Fig. 3B). Specifically, the non-supplemented group displayed a more negative slope, and higher $y$-intercept, than the supplemented group ( post hoc contrasts, $t>|2|, \quad P<0.02$; contrasts between supplemented exercised and supplemented non-exercised, $t=|1.9|$, $P<0.07)$. That is, pairs in the non-supplemented group had initially
Table 4. Type III tests of fixed effects for a mixed GLM predicting the concentration of vitamin $E$ in yolk

\begin{tabular}{lllrr}
\hline Effect & $\begin{array}{l}\text { Numerator } \\
\text { d.f. }\end{array}$ & $\begin{array}{l}\text { Denominator } \\
\text { d.f. }\end{array}$ & $F$-value & $P$-value \\
\hline Order & 1 & 61.9 & 39.34 & $<\mathbf{0 . 0 0 0 1}$ \\
Diet & 1 & 37.2 & 11.57 & $\mathbf{0 . 0 0 1 6}$ \\
Exercise & 1 & 37.2 & 0.06 & 0.8156 \\
Diet×exercise & 1 & 37.2 & 0.40 & 0.5309 \\
Order×diet & 1 & 61.9 & 10.79 & $\mathbf{0 . 0 0 1 7}$ \\
Order×exercise & 1 & 61.9 & 0.00 & 0.9606 \\
Order×diet×exercise & 1 & 61.9 & 0.31 & 0.5803 \\
\hline
\end{tabular}

Significant $P$-values $(\leq 0.05)$ are in bold.

higher concentrations of vitamin $\mathrm{E}$ in their eggs and concentration decreased more sharply over the laying order than for pairs in the supplemented group (Fig. 3B). Exercise treatment did not affect vitamin $\mathrm{E}$ concentration.

\section{Egg mass}

Egg mass did not change with laying order for non-supplemented pairs, but increased with laying order for supplemented pairs (order $\times$ diet, $F_{1,18.7}=12.77, P=0.0021$; Table 5, Fig. 3C). Among supplemented birds, egg mass increased at a greater rate in the exercised group than in the non-exercised group (post hoc specific contrast between slopes, $t_{16.8}=2.54, P=0.0212$ ), and eggs laid by exercised, supplemented birds were on average $\sim 154 \pm 68 \mathrm{mg}$ (mean \pm s.e.m.) heavier than those of non-exercised, supplemented birds (post hoc contrast of LS means, $t_{17}=2.28, P=0.0356$ ).

\section{Proportion of yolk in egg}

The proportion of yolk did not change with laying order (order, $F_{1,25.1}=1.39, P=0.2491$ ) or with exercise treatment (exercise, $F_{1,38}=0.31, P=0.5836$ ), but non-supplemented birds had a greater proportion of yolk in their eggs than supplemented birds (diet, $F_{1,38}=5.27, P=0.0273$ ). There was also suggested evidence of a diet $\times$ exercise interaction, whereby non-supplemented, nonexercised birds had the greatest proportion of yolk (30\%; Table 6) in their eggs (diet $\times$ exercise, $F_{1,38}=3.74, P=0.0606$ ). No other interactions were significant (order $\times$ diet, $F_{1,25.1}=0.00, P=0.9931$; order $\times$ exercise, $\quad F_{1,25.1}=0.24, \quad P=0.6277 ; \quad$ order $\times \operatorname{diet} \times$ exercise, $\left.F_{1,25.1}=3.25, P=0.0835\right)$.

\section{DISCUSSION}

Our experiment demonstrates for the first time that antioxidant supplementation and endurance flight together produce effects on allocation of lipid-soluble antioxidants to eggs by female zebra finches. Our results are consistent with hypothesis 1 in that oxidative damage was greater in exercised birds than in nonexercised birds after a 6 week training period. Our results were not

Table 5. Type III tests of fixed effects for a mixed GLM predicting egg mass

\begin{tabular}{|c|c|c|c|c|}
\hline Effect & $\begin{array}{l}\text { Numerator } \\
\text { d.f. }\end{array}$ & $\begin{array}{l}\text { Denominator } \\
\text { d.f. }\end{array}$ & $F$-value & $P$-value \\
\hline Order & 1 & 18.7 & 15.66 & 0.0009 \\
\hline Diet & 1 & 25.4 & 6.10 & 0.0205 \\
\hline Exercise & 1 & 25.4 & 0.17 & 0.6836 \\
\hline Diet $\times$ exercise & 1 & 25.4 & 0.28 & 0.6009 \\
\hline Order×diet & 1 & 18.7 & 12.77 & 0.0021 \\
\hline Order×exercise & 1 & 18.7 & 3.95 & 0.0617 \\
\hline Order×diet×exercise & 1 & 18.7 & 2.83 & 0.1094 \\
\hline
\end{tabular}

Significant $P$-values $(\leq 0.05)$ are in bold. 
Table 6. Effect of diet and exercise on yolk content of eggs

\begin{tabular}{lll}
\hline Exercised & $\begin{array}{l}\text { Supplemented } \\
(\%)\end{array}$ & $\begin{array}{l}\text { Non-supplemented } \\
(\%)\end{array}$ \\
\hline Yes & $26.31 \pm 0.99$ & $28.57 \pm 0.83$ \\
No & $26.94 \pm 0.83$ & $30.27 \pm 0.83$
\end{tabular}

Data are least square means \pm s.e.m. of the proportion of yolk as a percentage of whole egg mass in eggs laid by females that were fed diets supplemented or not supplemented with dietary antioxidants, and that were flown for $2 \mathrm{~h}$ each day for 6 weeks or were not flown.

consistent with hypothesis 2 in that birds fed the dietary antioxidant blend we provided had similar antioxidant capacity to that of birds that were not supplemented. Regarding hypothesis 3, we found that exercise and diet supplementation both directly affected female allocation of resources to eggs within a clutch, and we provide evidence that simultaneous consumption of water- and lipid-soluble antioxidants inhibits absorption of lipid-soluble compounds from the gut and thus allocation of lipid-soluble antioxidants to eggs. We discuss the ecological implications of these results, and how carryover effects have important implications for migratory birds.

\section{Hypothesis 1: does endurance flight pose an oxidative challenge?}

We predicted that exercised birds would have higher oxidative damage levels (measured as increased circulating hydroperoxides) than non-exercised birds after flight training, based on the hypothesis that flight poses an oxidative challenge. Consistent with this prediction, we found that exercised and non-exercised groups diverged in their damage levels after the 6 week flight training period, with exercised birds showing greater damage than non-exercised birds. The difference between the two groups is evident only during this time period because of a sizable decrease in variation within groups. Our data also suggest that male birds endure higher oxidative damage than female birds, which is not surprising, given that estrogen has been shown to have antioxidant effects by increasing levels of other antioxidants (particularly vitamin E) and directly scavenging pro-oxidants (Feingold et al., 1993; Tiidus, 1995; Behl et al., 1997; Halifeoglu et al., 2003).

Oxidative damage has been widely assumed to occur in volant birds after extended periods of exercise, but rarely has it been explicitly demonstrated (Costantini et al., 2008, 2013; Jenni-Eiermann et al., 2014). Even with dietary antioxidant supplementation, the increased metabolic demand of flight appears to have damaged lipids in our study; repairing damage is probably then an unavoidable cost of long flights, with which migratory birds simply must cope. Skrip et al. (2015) showed that wild garden warblers (Sylvia borin) on stopover were able to decrease the same oxidative damage marker in a matter of days after crossing the Mediterranean Sea, indicating some ability to recover from oxidative damage associated with long flights.

\section{Hypothesis 2: do dietary antioxidants increase overall antioxidant protection in birds?}

We expected that birds supplemented with polyphenols would have higher circulating non-enzymatic antioxidant capacity and lower oxidative damage than non-supplemented birds, based on the hypothesis that the polyphenols we supplied would increase antioxidant protection, as seen by Beaulieu and Schaefer (2014) for Gouldian finches (Erythrura gouldiae). However, our results were not consistent with theirs, perhaps because of the mode of antioxidant delivery. Dissolving polyphenol extracts in water does lead to absorption of those polyphenols and their circulation in blood, as has been shown in other systems (Murkovic et al., 2001; Milbury et al., 2002), and hence we chose to use this delivery method. Other studies in birds, however, have delivered polyphenols in food (Catoni et al., 2008; Beaulieu and Schaefer, 2014). Given that the absorption of phenolic compounds can depend on associated sugars (He et al., 2006), it is possible that the absence of a natural food matrix (and associated micronutrient and macronutrient content) resulted in lower absorption of dietary antioxidants in our study than in those previous bird studies.

It is also possible that the antioxidant capacity of our experimental birds was at an upper limit and could not be increased by supplementation or that antioxidant capacity was maintained by compensatory changes in the contribution of endogenous and dietary antioxidants. The OXY values we observed were greater than those reported by Beaulieu and Schaefer (2014) and generally higher and less variable than those observed in wild red-eyed vireos (Vireo olivaceus) and blackpoll warblers (Setophaga striata) preparing for migration at an autumn stopover site (Skrip et al., 2015). OXY accounts for both dietary and endogenous contributions to antioxidant capacity (excluding uric acid), and therefore it is possible that supplemented birds relied less on endogenous micromolecular antioxidants given the dietary antioxidants we supplied. Determining an animal's reliance on endogenous versus dietary antioxidants would require measuring specific compounds (e.g. glutathione, phenolics, vitamin E) circulating in the plasma (Skrip and McWilliams, 2016). Recent work also suggests that tests like OXY may not fully capture the antioxidant action of lipophilic compounds (Tomášek et al., 2016).

Exercised and non-exercised birds had antioxidant capacity and antioxidant enzyme activity similar to each other during all three phases of the experiment, although we did observe that circulating antioxidant capacity dropped in non-exercised birds but not in exercised birds during exercise training, based on the tests of effect slices (Fig. 2B). During this time, birds were deprived of food and water for approximately two non-consecutive hours mid-day while training took place. Non-exercised birds maintained their body mass during this time period, while exercised birds lost mass during training and then returned to their pre-training mass after breeding (RM ANOVA, time $\times$ exercise, $F_{2,64}=3.61, P=0.0327$; data not shown). Lower antioxidant capacity among non-exercised birds, therefore, was not associated with body mass but with some other, unknown, endogenous change.

\section{Hypothesis 3: do flight and diet affect subsequent egg composition?}

Our experiment revealed for the first time that flight exercise and supplementation with a combination of water- and lipid-soluble dietary antioxidants affect the allocation of lipid-soluble antioxidants in eggs by female songbirds. We found several important effects, but not those we anticipated. We expected that birds supplemented with water- and lipid-soluble antioxidants would lay eggs with higher lipid-soluble antioxidant concentrations than non-supplemented birds; indeed, we found the opposite. The notion that exercised birds must expend some of their antioxidant capacity and thus subsequently would lay eggs with lower antioxidant concentrations than non-exercised birds was only partially supported; exercise affected deposition of lutein but not vitamin E.

Determining the effects of exercise and diet on female allocation to eggs requires careful consideration of how egg composition changes with laying order within a given clutch. Lutein and vitamin 
E concentrations decreased with laying order, as has been found in many other studies with captive zebra finches (Royle et al., 2003; Blount et al., 2006; Williamson et al., 2006), wild passerines (barn swallow, Hirundo rustica: Saino et al., 2002; red-winged blackbird Agelaius phoeniceus: Newbrey et al., 2015) and non-passerines (gulls: Royle et al., 2001). We found, however, that exercise and diet supplementation affected the rate of decrease in egg antioxidants with laying order; that is, the treatments affected the relative amount of antioxidants that females deposited into each consecutive egg.

\section{Diet effects}

Contrary to expectations, we found dietary supplementation lowered lutein and vitamin $\mathrm{E}$ concentrations in eggs, compared with non-supplemented controls (Fig. 3A,B). Given that we provided lutein in the supplement, we predicted that supplemented birds would deposit greater lutein concentrations in eggs (e.g. McGraw et al., 2005; Royle et al., 2003). We suggest that the reduction in the concentration of lipid-soluble antioxidants deposited in eggs occurred because of a negative effect of watersoluble antioxidants on the absorption of lipid-soluble antioxidants from the gut. Ours is the first experiment to combine water-soluble antioxidants (flavonoids, including anthocyanins and catechins) and lipid-soluble antioxidants (carotenoids including lutein) into one supplement for songbirds. We did so because free-living birds regularly encounter foods containing both types of antioxidants (e.g. fruits; Alan et al., 2013). The results of our study are consistent with the hypothesis that water-soluble flavonoids in the supplement interfered with the absorption of lipids and lipid-soluble antioxidants from the gut, and so supplemented birds actually assimilated less of the lipid-soluble antioxidants available in their diet (not only in the supplement but also from the standard seed mixture and the kale) than birds not receiving flavonoids.

Fat-soluble antioxidants like vitamin E and carotenoids are assimilated via micelles formed in the intestine by dietary lipids (Surai, 2002). Past studies in poultry and rats have found that catechins (one sub-class of polyphenolic antioxidants in the extract we provided) interfere with the assimilation of lipids from micelles, thereby lowering cholesterol absorption from the gut and causing chickens (Gallus gallus domesticus) to lay eggs with lower yolk cholesterol and yolk lipids (Bravo, 1998; Biswas et al., 2000; Koo and Noh, 2007). This effect may not be restricted to catechins, given that a study with non-flavonoids found similar evidence: when fed resveratrol (a stilbene-type polyphenol), quail (Coturnix coturnix japonica) laid eggs with narrower yolks than non-resveratrol-fed birds; yolks were narrower as supplementation increased from 200 to $400 \mathrm{mg} \mathrm{kg}^{-1}$ (Sahin et al., 2010). We found that water-soluble antioxidant (i.e. flavonoid) supplementation decreased the deposition of both vitamin $\mathrm{E}$ and lutein, and furthermore that such supplementation decreased the proportion of yolk in eggs; this evidence supports the idea that supplementation with water-soluble antioxidants lowered the amount of fat-soluble compounds that could be deposited in eggs when these compounds interacted in the intestine.

Although wild birds encounter both water- and lipid-soluble antioxidants in their diet, and often in the same food items (e.g. fruits; Alan et al., 2013), it may behoove them to be choosy about the timing of polyphenol consumption, or to ensure that they consume enough fat to compensate for any inhibitory effects on absorption. Beaulieu and Schaefer (2014) found that captive Gouldian finches chose to consume calorie-poor seeds rich in polyphenolic antioxidants during the middle of the day, and calorie-rich, polyphenolic-poor seeds during the morning and evening; the researchers concluded that birds were free to increase their antioxidant capacity only when their caloric needs were satisfied. Our study may provide further insight into their results, by suggesting that songbirds may better assimilate calories when not simultaneously consuming polyphenols and that birds may be capable of making the best temporal dietary decisions when presented a choice. Further experiments would be necessary to determine by what percentage polyphenols lower the assimilation efficiency of fat-soluble compounds and how consumption of different types of antioxidants affects birds' dietary decisions, but it is apparent that the polyphenols we supplied in the drinking water affected how zebra finches were able to allocate lutein and vitamin $\mathrm{E}$ to tissues.

For the first time in songbirds, we have shown that consumption of water-soluble polyphenols decreased allocation of lipid-soluble antioxidants (lutein and vitamin E) to eggs, presumably because those polyphenols interfere with the absorption of lipid-soluble antioxidants in the intestine. This finding has important implications for migratory birds consuming polyphenols along with fat-soluble antioxidants on stopover sites; our results suggest that at least some sub-classes of polyphenols do not provide an additive antioxidant benefit when consumed - because they hinder the absorption of fat-soluble antioxidants and fats themselves. Clearly, complicated interactions occur among molecules during digestion, and our findings should help researchers to more deeply consider what actual nutrition birds receive from the fruits and other foods they eat, depending on their composition.

\section{Exercise effects}

Our experiment also demonstrated that flight exercise lowered lutein, but not vitamin E, deposition in eggs. Among nonsupplemented birds, lutein concentration in eggs was clearly lower for exercised birds than for non-exercised controls (Fig. 3A). We predicted that exercised birds would deposit fewer antioxidants into eggs because fewer should be available after the oxidative challenge of flight, but we did not anticipate a difference in deposition depending on the compound.

There are two possible, non-mutually exclusive, explanations for the disparity between exercise effects on lutein and vitamin E. (1) It is very likely that by burning fat to fly, the exercised birds in our experiment reduced lutein stores available to then deposit into their eggs. In birds, vitamin E is largely stored in the liver, whereas lutein is stored in subcutaneous body fat, and can be mobilized from fat in times of need (Metzger and Bairlein, 2011). A female zebra finch's fat score is predictive of the lutein concentration in her eggs but not the vitamin E concentration (Williamson et al., 2006), demonstrating the importance of body fat stores to lutein deposition in eggs. We did not measure changes in fat stores in this study, but it is well accepted that birds, unlike other exercising vertebrates, rely primarily on fats for fuel. (2) Although carotenoids and vitamin E work together to protect lipids during oxidative challenges, oxidized vitamin $\mathrm{E}$ can be recycled to its active form by carotenoids and other compounds, whereas carotenoids may take on a pro-oxidant nature (Surai, 2002). It is possible that the oxidative challenge of flight eliminated carotenoids such as lutein, but not vitamin E, from the birds' antioxidant reservoirs, reducing their availability for deposition. Carotenoids are important contributors to sexual signaling in zebra finches (McGraw et al., 2004), and mate attractiveness can influence maternal investment in eggs (e.g. Williamson et al., 2006). At the time of breeding in our experiment, however, we found no statistical difference in beak redness between treatment groups (as measured by a portable reflectance spectrophotometer; data not shown). 
Although zebra finches are not migratory, our exercise findings likely have important implications for studies of migratory birds, if they share similar mechanisms of antioxidant storage and lipid metabolism. Researchers commonly consider leftover fat stores advantageous to female songbirds after spring migration, given that greater energy stores enable them to overcome food shortages or potentially produce higher quality eggs. Our data suggest that female birds with high residual fat stores may also be better able to provision their eggs with lutein, an important antioxidant, given that lutein is stored in body fat (Metzger and Bairlein, 2011). We therefore hypothesize that wild female birds might accumulate both fat-soluble antioxidants and lipid stores prior to migration for the dual purposes of long-duration flight and subsequent egg production. Such a strategy may be particularly important for long-distance migrants that must lay their clutch soon after they arrive on breeding grounds.

\section{Could birds compensate for lower antioxidant concentration?}

Although we found that diet supplementation with antioxidants and exercise decreased deposition of lipid-soluble antioxidants to eggs, we did find another surprising effect: supplemented exercised birds invested the most mass in later-laid eggs (Fig. 3C). In the nonsupplemented group, regardless of exercise treatment, eggs had the same mass regardless of laying order. In contrast, egg mass increased with egg order for supplemented birds, and a post hoc test showed that the increase was even more pronounced in the exercised supplemented group. For five of the nine clutches in the supplemented group and one clutch in the non-supplemented group, the last-laid egg contained equal or greater total values of lutein and/or vitamin $\mathrm{E}$ than the first-laid egg, suggesting that some females were able to compensate for lower yolk concentrations of lipid-soluble antioxidants by increasing the total mass of yolk. It is also likely that the heavier later-laid eggs across all clutches in the supplemented group contained more energy or other nutrients that we did not measure than the first-laid eggs, and therefore other compensatory mechanisms were at work. This differential allocation across the clutch could impact offspring fitness by improving survival of later-hatched nestlings, which are typically disadvantaged in this asynchronously hatching species (Royle et al., 2003; Rutstein et al., 2004; Williamson et al., 2006, 2008). We did not allow any eggs to hatch, and so effects of parental exercise and polyphenol supplementation on offspring survival, growth and fitness remain unknown.

\section{Conclusions}

Our experiment provides several insights into the physiology of volant, breeding songbirds. First, we explicitly demonstrated that exercised birds had higher oxidative damage than non-exercised birds after 6 weeks of flight training. Second, consumption of watersoluble flavonoids, antioxidant compounds commonly found in wild foods, decreased the deposition of lipid-soluble antioxidants (lutein and vitamin E) into eggs and decreased relative yolk size. For the first time, we provide evidence that simultaneous consumption of water- and lipid-soluble antioxidants inhibits absorption and thus allocation of lipid-soluble antioxidants to songbird eggs. Third, we show for the first time that flight exercise by songbirds had a carryover effect on reproduction, lowering deposition of lutein into eggs. These findings have important implications for future studies of wild birds during migration and other oxidative challenges.

\section{Acknowledgements}

We thank the following student assistants for their help with animal care and sample processing: A. Adil, I.-R. Armitstead, M. Beatty, D. Catizone, P. Masse, A. O'Connor and L. Zhang. Thanks go to the following members of the McWilliams lab for assistance with tissue sampling: B. Alan, J. Beuth, B. Buffum, J. Hall, P. Loring, R. Masse, S. Richman, A. Smith and K. Winiarski. We thank T. Skrip, G. Skrip and B. Skrip for help with aviary construction; J. Atoyan, D. Bourassa and the staff of Critter Hut Aquarium \& Pets (Narragansett, RI, USA) for help with project logistics; and P. Pooler Eisenbies and A. Smith for statistical advice. Dietary antioxidants were donated by their respective suppliers, Artemis International Inc. (Fort Wayne, IN, USA) and DSM Nutritional Products Ltd (Parsippany, NJ, USA).

\section{Competing interests}

The authors declare no competing or financial interests.

\section{Author contributions}

M.M.S. and S.R.M. designed the experiment; M.M.S. performed the experiment conducted the plasma and liver assays, analyzed the data and prepared the manuscript; N.P.S., T.Y. and H.M. conducted the egg assays; M.M.S., S.R.M., N.P.S., T.Y. and H.M. revised the manuscript.

Funding

This research was supported by an American Ornithologists' Union Research Award to M.M.S. and a Grant-in-Aid of Research to M.M.S. from the National Academy of Sciences, administered by Sigma Xi, The Scientific Research Society. During data collection and writing of the manuscript, M.M.S. and S.R.M. were supported by the National Science Foundation (IOS-0748349 and IOS-135417 to S.R.M.) and U.S. Department of Agriculture (RIAES-538748 to S.R.M.)

\section{Data availability}

Data are available from the Dryad digital repository: http://dx.doi.org/10.5061/dryad d4600

\section{References}

Alan, R. R., McWilliams, S. R. and McGraw, K. J. (2013). The importance of antioxidants for avian fruit selection during autumn migration. Wilson J. Ornithol. 125, 513-525.

Bauchinger, U., Van't Hof, T. and Biebach, H. (2009). Food availability during migratory stopover affects testis growth and reproductive behaviour in a migratory passerine. Horm. Behav. 55, 425-433.

Bauchinger, U., Keil, J., McKinney, R. A., Starck, J. M. and McWilliams, S. R. (2010). Exposure to cold but not exercise increases carbon turnover rates in specific tissues of a passerine. J. Exp. Biol. 213, 526-534.

Beaulieu, M. and Schaefer, H. M. (2013). Rethinking the role of dietary antioxidants through the lens of self-medication. Anim. Behav. 86, 17-24.

Beaulieu, M. and Schaefer, H. M. (2014). The proper time for antioxidant consumption. Physiol. Behav. 128, 54-59.

Behl, C., Skutella, T., Lezoualc'h, F., Post, A., Widmann, M., Newton, C. J. and Holsboer, F. (1997). Neuroprotection against oxidative stress by estrogens: structure-activity relationship. Mol. Pharmacol. 51, 535-541.

Berthouly, A., Helfenstein, F. and Richner, H. (2007). Cellular immune response, stress resistance and competitiveness in nestling Great Tits in relation to maternally transmitted carotenoids. Funct. Ecol. 21, 335-343.

Berthouly, A., Cassier, A. and Richner, H. (2008). Carotenoid-induced maternal effects interact with ectoparasite burden and brood size to shape the tradeoff between growth and immunity in nestling Great Tits. Funct. Ecol. 22, 854-863.

Biswas, Md. A. H., Miyazaki, Y., Nomura, K. and Wakita, M. (2000). Influences of long-term feeding of Japanese green tea powder on laying performance and egg quality in hens. Asian-Aus. J. Anim. Sci. 13, 980-985.

Blount, J. D. and Matheson, S. M. (2006). Effects of carotenoid supply on escape flight responses in zebra finches, Taeniopygia guttata. Anim. Behav. 72, 595-601. Blount, J. D., Metcalfe, N. B., Arnold, K. E., Surai, P. F., Devevey, G. L. and Monaghan, P. (2003). Neonatal nutrition, adult antioxidant defences and sexual attractiveness in the zebra finch. Proc. R. Soc. B Biol. Sci. 270, 1691-1696.

Blount, J. D., Metcalfe, N. B., Arnold, K. E., Surai, P. F. and Monaghan, P. (2006). Effects of neonatal nutrition on adult reproduction in a passerine bird. Ibis 148 , 509-514.

Bolser, J. A., Alan, R. R., Smith, A. D., Li, L., Seeram, N. P. and McWilliams, S. R. (2013). Birds select fruits with more anthocyanins and phenolic compounds during autumn migration. Wilson J. Ornithol. 125, 97-108.

Bravo, L. (1998). Polyphenols: chemistry, dietary sources, metabolism, and nutritional significance. Nutr. Rev. 56, 317-333.

Catoni, C., Schaefer, H. M. and Peters, A. (2008). Fruit for health: the effect of flavonoids on humoral immune response and food selection in a frugivorous bird. Funct. Ecol. 22, 649-654.

Costantini, D., Cardinale, M. and Carere, C. (2007). Oxidative damage and antioxidant capacity in two migratory bird species at a stop-over site. Comp. Biochem. Phys. C 144, 363-371.

Costantini, D., Dell'Ariccia, G. and Lipp, H.-P. (2008). Long flights and age affect oxidative status of homing pigeons (Columba livia). J. Exp. Biol. 211, 377-381. 
Costantini, D., Monaghan, P. and Metcalfe, N. B. (2013). Loss of integration is associated with reduced resistance to oxidative stress. J. Exp. Biol. 216, 2213-2220

Ebbinge, B. S. and Spaans, B. (1995). The importance of body reserves accumulated in spring staging areas in the temperate zone for breeding in DarkBellied Brent Geese Branta b. bernicla in the high Arctic. J. Avian Biol. 26 105-113.

Feingold, I. B., Longhurst, P. A. and Colby, H. D. (1993). Regulation of adrenal and hepatic alpha-tocopherol content by androgens and estrogens. Biochim. Biophys. Acta 1176, 192-196.

Gil, D., Heim, C., Bulmer, E., Rocha, M., Puerta, M. and Naguib, M. (2004). Negative effects of early developmental stress on yolk testosterone levels in a passerine bird. J. Exp. Biol. 207, 2215-2220.

Griffith, S. C. and Buchanan, K. L. (2010). The zebra finch: the ultimate Australian supermodel. Emu 110, v-xii.

Halifeoglu, I., Karatas, F., Canatan, H., Colak, R. and Karadas, E. (2003) Investigation of antioxidant vitamins (A, E and C) and selenium levels in chickens receiving estrogen or testosterone. Cell Biochem. Funct. 21, 133-136.

Harrison, X. A., Blount, J. D., Inger, R., Norris, D. R. and Bearhop, S. (2011) Carry-over effects as drivers of fitness differences in animals. J. Anim. Ecol. 80 , 4-18.

He, J., Magnuson, B. A., Lala, G., Tian, Q., Schwartz, S. J. and Giusti, M. M. (2006). Intact anthocyanins and metabolites in rat urine and plasma after 3 months of anthocyanin supplementation. Nutr. Cancer 54, 3-12

Jacob, S., Parthuisot, N., Vallat, A., Ramon-Portugal, F., Helfenstein, F. and Heeb, P. (2015). Microbiome affects egg carotenoid investment, nestling development and adult oxidative costs of reproduction in Great tits. Funct. Ecol. 29, 1048-1058.

Jenni-Eiermann, S., Jenni, L., Smith, S. and Costantini, D. (2014). Oxidative stress in endurance flight: an unconsidered factor in bird migration. PLOS ONE 9 e97650.

Koo, S. I. and Noh, S. O. (2007). Green tea as inhibitor of the intestinal absorption of lipids: potential mechanism for its lipid-lowering effect. J. Nutr. Biochem. 18, 179-183

Koutsos, E. A., Clifford, A. J., Calvert, C. C. and Klasing, K. C. (2003). Materna carotenoid status modifies the incorporation of dietary carotenoids into immune tissues of growing chickens (Gallus gallus domesticus). J. Nutr. 133, 1132-1138.

Larcombe, S. D., Coffey, J. S., Bann, D., Alexander, L. and Arnold, K. E. (2010). Impacts of antioxidants and flight training on post-exercise oxidative damage. Comp. Biochem. Phys. B 155, 49-53.

Legagneux, P., Fast, P. L. F., Gauthier, G. and Bêty, J. (2012). Manipulating individual state during migration provides evidence for carry-over effects modulated by environmental conditions. Proc. R. Soc. Lond. B Biol. Sci. 279, 876-883.

Marri, V. and Richner, H. (2014). Yolk carotenoids increase fledging success in Great Tit nestlings. Oecologia 176, 371-377.

McGraw, K. J., Hill, G. E., Stradi, R. and Parker, R. S. (2001). The influence of carotenoid acquisition and utilization on the maintenance of species-typical plumage pigmentation in male American goldfinches (Carduelis tristis) and northern cardinals (Cardinalis cardinalis). Physiol. Biochem. Zool. 74, 843-852.

McGraw, K. J., Hill, G. E., Navara, K. J. and Parker, R. S. (2004). Differential accumulation and pigmenting ability of dietary carotenoids in colorful finches. Physiol. Biochem. Zool. 77, 484-491.

McGraw, K. J., Adkins-Regan, E. and Parker, R. S. (2005). Maternally derived carotenoid pigments affect offspring survival, sex ratio, and sexual attractiveness in a colorful songbird. Naturwissenschaften 92, 375-380.
Metzger, B. J. and Bairlein, F. (2011). Fat stores in a migratory bird: a reservoir of carotenoid pigments for times of need? J. Comp. Physiol. B 181, 269-275.

Milbury, P. E., Cao, G., Prior, R. L. and Blumberg, J. (2002). Bioavailablility of elderberry anthocyanins. Mech. Ageing Dev. 123, 997-1006.

Murkovic, M., Mülleder, U., Adam, U. and Pfannhauser, W. (2001). Detection of anthocyanins from elderberry juice in human urine. J. Sci. Food Agric. 81, 934-937.

Newbrey, J. L., Paszkowski, C. A., McGraw, K. J. and Ogle, S. (2015). Layingsequence variation in yolk carotenoids and egg characteristics in the red-winged blackbird Agelaius phoeniceus. J. Avian Biol. 46, 46-54

Nudds, R. L. and Bryant, D. M. (2000). The energetic cost of short flights in birds J. Exp. Biol. 203, 1561-1572.

Royle, N. J., Surai, P. F. and Hartley, I. R. (2001). Maternally derived androgens and antioxidants in bird eggs: complementary but opposing effects? Behav. Ecol. 12, 381-385

Royle, N. J., Surai, P. F. and Hartley, I. R. (2003). The effect of variation in dietary intake on maternal deposition of antioxidants in zebra finch eggs. Funct. Ecol. 17 472-481.

Rutstein, A. N., Slater, P. J. B. and Graves, J. A. (2004). Diet quality and resource allocation in the zebra finch. Proc. R. Soc. Lond. B Biol. Sci. 271, S286-S289.

Sahin, K., Akdemir, F., Orhan, C., Tuzcu, M., Hayirli, A. and Sahin, N. (2010). Effects of dietary resveratrol supplementation on egg production and antioxidant status. Poultry Sci. 89, 1190-1198.

Saino, N., Bertacche, V., Ferrari, R. P., Martinelli, R., Møller, A. P. and Stradi, R. (2002). Carotenoid concentration in Barn Swallow eggs is influenced by laying order, maternal infection and paternal ornamentation. Proc. R. Soc. Lond. B Biol. Sci. 269, 1729-1733.

Saino, N., Ferrari, R., Romano, M., Martinelli, R. and Møller, A. P. (2003) Experimental manipulation of egg carotenoids affects immunity of barn swallow nestlings. Proc. R. Soc. Lond. B Biol. Sci. 270, 2485-2489.

Sandell, M. I., Adkins-Regan, E. and Ketterson, E. D. (2007). Pre-breeding diet affects the allocation of yolk hormones in zebra finches Taeniopygia guttata. J. Avian Biol. 38, 284-290.

Schaefer, H. M., McGraw, K. and Catoni, C. (2008). Birds use fruit colour as honest signal of dietary antioxidant rewards. Funct. Ecol. 22, 303-310.

Skrip, M. M. and McWilliams, S. R. (2016). Oxidative balance in birds: an atoms-toorganisms-to-ecology primer for ornithologists. J. Field Ornithol. 87, 1-20.

Skrip, M. M., Bauchinger, U., Goymann, W., Fusani, L., Cardinale, M., Alan, R. R. and McWilliams, S. R. (2015). Migrating songbirds on stopover prepare for, and recover from, oxidative challenges posed by long-distance flight. Ecol. Evol. $\mathbf{5}$ 3198-3209.

Surai, P. F. (2002). Natural Antioxidants in Avian Nutrition and Reproduction Nottingham, UK: Nottingham University Press.

Tiidus, P. M. (1995). Can estrogens diminish exercise induced muscle damage? Can. J. Appl. Physiol. 20, 26-38.

Tomášek, O., Gabrielová, B., Kačer, P., Maršík, P., Svobodová, J., Syslová, K., Vinkler, M. and Albrecht, T. (2016). Opposing effects of oxidative challenge and carotenoids on antioxidant status and condition-dependent sexual signalling. Sci. Rep. 6, 23546.

Williamson, K. A., Surai, P. F. and Graves, J. A. (2006). Yolk antioxidants and mate attractiveness in the zebra finch. Funct. Ecol. 20, 354-359.

Williamson, K., Gilbert, L., Rutstein, A. N., Pariser, E. C. and Graves, J. A (2008). Within-year differences in reproductive investment in laboratory zebra finches (Taeniopygia guttata), an opportunistically breeding bird. Naturwissenschaften 95, 1143-1148.

Zann, R. A. (1996). The Zebra Finch: A Synthesis of Field and Laboratory Studies. Oxford, UK: Oxford University Press. 